\title{
Sustainable Electrochemical Extraction of Lithium from Natural Brine for Renewable Energy Storage
}

\author{
V. C. E. Romero, ${ }^{1}$ M. Tagliazucchi, $\circledast^{2}$ V. Flexer, $\oplus^{1}$ and E. J. Calvo $\oplus^{2, *, z}$ \\ ${ }^{1}$ Centro de Investigación y Desarrollo en Materiales Avanzados y Almacenamiento de Energía de Jujuy-CIDMEJu \\ (CONICET-Universidad Nacional de Jujuy), Centro de Desarrollo Tecnológico General Savio, Palpalá, Jujuy \\ AR-4612, Argentina \\ ${ }^{2}$ INQUIMAE (CONICET-Universidad de Buenos Aires), Ciudad Universitaria, AR-1428 Buenos Aires, Argentina
}

An electrochemical reactor for the extraction of lithium from natural brine has been designed. It comprises two 3D porous packed bed electrodes and a porous separator filled with electrolyte. The electrodes are filled with conducting petroleum coke particles covered respectively with $\mathrm{LiMn}_{2} \mathrm{O}_{4}$ selective to lithium ions and polypyrrole selective to anions. It operates in two steps: First, the porous electrodes and the separator are filled with natural brine to extract $\mathrm{Li}^{+}$and $\mathrm{Cl}^{-}$by intercalation and adsorption. Then, after rinsing with water the reactor is filled with a dilute $\mathrm{LiCl}$ recovery solution and $\mathrm{LiCl}$ is recovered by reversing the electrical current. A mathematical model for the reactor comprising the Nernst-Planck equation and the battery intercalation model has been developed. The model was solved using the finite element method under the COMSOL Multiphysics environment in order to obtain the electrostatic potential and the ion currents and concentrations across the system. Unlike the asymmetric $\mathrm{LiMn}_{2} \mathrm{O}_{4} /$ activated carbon super-capacitor, in the lithium extracting reactor the total $\mathrm{LiCl}$ concentration decreases in the extraction step and increases in the recovery step. A good agreement between the experimental and simulated potential difference vs. time at constant current validates the model of the reactor.

(C) The Author(s) 2018. Published by ECS. This is an open access article distributed under the terms of the Creative Commons Attribution 4.0 License (CC BY, http://creativecommons.org/licenses/by/4.0/), which permits unrestricted reuse of the work in any medium, provided the original work is properly cited. [DOI: $10.1149 / 2.0741810 \mathrm{jes}]$

(cc) BY

Manuscript submitted May 29, 2018; revised manuscript received July 9, 2018. Published July 24, 2018.

In the past 25 years lithium ion batteries have changed the way we communicate, with the cell phone as an icon of that revolution in communications and portable electronics. In the next 25 years electric vehicles are expected to change our everyday mobility with the electric car as icon. Each electric car has a battery with some $6.5 \mathrm{~kg}$ of lithium, enough to power several thousand mobile phones which depicts the magnitude of the challenge. ${ }^{1}$ Therefore, if lithium batteries will enable electric mobility and a wide spread use of renewable intermittent energy sources, smart grids and remote electrification the extraction of lithium should also be sustainable.

The present soda-lime slow evaporation process from lithium containing high altitude salt flats brine, is not inert to the environment since millions of gallons of water are lost by evaporation in a desert, chemicals are added to remove magnesium and precipitate lithium carbonate and chemical wastes are produced. ${ }^{2-4}$ The lowest production cost by brine evaporation in Chile is 3,000 dollars per ton of lithium carbonate by evaporation with sun radiation during several months, according to Accenture report. ${ }^{5}$ Therefore, there is an intense search for new fast methods to extract lithium without affecting the environment, among which electrochemical approaches will play a key role.

Different electrochemical strategies have been suggested: Kanoh ${ }^{6,7}$ reported the insertion of lithium ions into an electrochemical $\mathrm{Pt} / \lambda-\mathrm{MnO}_{2}$ cell and studied the kinetics of lithium insertion/extraction from $\lambda-\mathrm{MnO}_{2} / \mathrm{LiMn}_{2} \mathrm{O}_{4}$ in $\mathrm{LiCl}$ aqueous solutions. ${ }^{8} \mathrm{La}$ Mantia and co-workers $^{9-11}$ used an entropic cell to extract lithium with battery electrodes: $\mathrm{LiFePO}_{4}$ cathode and $\mathrm{Ag} / \mathrm{AgCl}$ reversible chloride anode for the selective recovery process, and also have recently described a nickel hexacyanoferrate anode as alternative to the silver anode. ${ }^{12} \mathrm{~A}$ similar $\lambda-\mathrm{MnO}_{2} / \mathrm{Ag}$ battery was reported by Lee and co-workers for artificial brine, or $\lambda$ - $\mathrm{MnO}_{2}$ /activated carbon hybrid super capacitor. ${ }^{13}$ A highly selective $\mathrm{Li} / \mathrm{Na}$ electrochemical process based on olivine $\mathrm{LiFePO}_{4}$ coated with polydopamine with the $\mathrm{I}^{-} / \mathrm{I}_{3}{ }^{-}$redox couple separated by a membrane has been disclosed. ${ }^{14}$ Hoshino proposed an electro-dialysis method using an ionic liquid based membrane technology ${ }^{15,16}$ Fast and efficient chemical redox insertion of lithium ions into solid $\mathrm{FePO}_{4}$ has been reported by Owen and co-workers. ${ }^{17}$ A different approach with an electrochemical cell with both lithium containing electrolytes separated by an anion exchange membrane and using two $\mathrm{LiFePO}_{4} / \mathrm{FePO}_{4}{ }^{18}$ or $\lambda-\mathrm{MnO}_{2} / \mathrm{LiMn}_{2} \mathrm{O}_{4}{ }^{19}$ has been put forward for the extraction of $\mathrm{Li}$ from brine.

$\mathrm{LiMn}_{2} \mathrm{O}_{4}$ (LMO) has also been reported as a matrix for the isotopic separation of ${ }^{6} \mathrm{Li} /{ }^{7} \mathrm{Li}$ with the lighter isotope, ${ }^{6} \mathrm{Li}$, preferentially fractionated to the electrolyte solution phase, with the value of the $\mathrm{Li}$ isotope separation factor ranging from 0.989 to 0.971 at $25^{\circ} \mathrm{C} .^{20}$

Electrochemical ion transfer junction (EIJ) of lithium from concentrate to dilute $\mathrm{LiCl}$ electrolyte in a one step process uses a $\mathrm{LiMn}_{2} \mathrm{O}_{4}$ containing membrane as reported by Guyot et al. ${ }^{21}$ Electrodialysis, ${ }^{22}$ membrane capacitive deionization (MCDI) ${ }^{23,24}$ and reverse osmosis ${ }^{25}$ have also been considered.

An alternative electrochemical method for the extraction of lithium chloride from brine or sea water has been developed recently in our research laboratory. ${ }^{26,27}$ In this electrochemical method, which is fast, efficient, has low environmental impact and low energy consumption, $\mathrm{LiCl}$ rich brine is the electrolyte of an undivided electrochemical cell comprised of a lithium deficient $\mathrm{Li}_{1-\mathrm{x}} \mathrm{Mn}_{2} \mathrm{O}_{4}$ (LMO) cathode selective to lithium ions and a chloride ion reversible polypyrrole (PPy) electrode. A two-step electrochemical process extracts lithium chloride selectively from natural brine and then recovers high purity $\mathrm{LiCl}$ in a dilute electrolyte. In the first step the exchange of chloride at the oxidized PPy electrode takes place simultaneously to lithium intercalation at $\mathrm{LMO}$ with high selectivity, thus extracting $\mathrm{LiCl}$ only from natural brine. In a second step, after rinsing the electrodes thoroughly the brine electrolyte is replaced with a dilute $\mathrm{LiCl}$ recovery solution and the electrode potential is reversed, so that lithium is released from the $\mathrm{LiMn}_{2} \mathrm{O}_{4}$ anode and chloride ions from the PPy cathode. During the lithium chloride uptake, only $\mathrm{Li}^{+}$ions are selectively intercalated at the cathode and $\mathrm{Cl}^{-}$ions are exchanged at the anode while the release of $\mathrm{LiCl}$ into the recovery electrolyte takes place in the second step. Under a potential difference of less than $1 \mathrm{~V}$, intercalation of lithium ions in the $\mathrm{Li}_{1-\mathrm{X}} \mathrm{Mn}_{2} \mathrm{O}_{4}$ electrode takes place.

For the extraction process the reactions are: ${ }^{26,27}$

$$
\begin{aligned}
& x \mathrm{Li}^{+}(\text {brine })+\mathrm{Li}_{1-x} \mathrm{Mn}_{1-x}^{I I I} \mathrm{Mn}_{1+x}^{I V} \mathrm{O}_{4}+x e^{-} \text {(cathode) } \\
& \leftrightharpoons \mathrm{LiMn}^{I V} \mathrm{Mn}^{I I I} \mathrm{O}_{4}
\end{aligned}
$$

and, 
with the overall process:

$$
\begin{aligned}
& x \mathrm{Li}^{+}(\text {brine })+x \mathrm{Cl}^{-}(\text {brine })+\mathrm{Li}_{1-x} \mathrm{Mn}_{1-x}^{I I I} \mathrm{Mn}_{1+x}^{I V} \mathrm{O}_{4}+x P P y^{0} \\
& \leftrightharpoons \mathrm{LiMn}^{I V} \mathrm{Mn}^{\mathrm{III}} \mathrm{O}_{4}+x\left[P P y^{+} \mathrm{Cl}^{-}\right]
\end{aligned}
$$

A hybrid $\mathrm{LiMn}_{2} \mathrm{O}_{4}$ battery electrode and carbon high capacitance electrode has also been proposed for an energy storage supercapacitor. $^{28,29}$ However, the use of polypyrrole (PPy) instead of carbon electrode as anion selective counter electrode in our strategy, operates at low overpotential and the lithium extracting device has cell voltage at less than $1 \mathrm{~V} .^{27}$

Once fulfilled the proof of concept, ${ }^{26,27,30,31}$ in the present paper we move forward from the fundamental concept previously described toward the implementation of the proposed method in an electrochemical reactor comprised of packed bed electrodes. In this design, a carbon conducting support is loaded with LMO as lithium capturing material and PPy grown on the carbon conducting support, with brine or recovery solution alternately filling both porous electrodes.

Experimental results of the extraction electrochemical reactor operating under constant current are presented together with numerical simulations of the reactor operation using a finite element method under COMSOL multiphysics environment. Unlike a lithium battery or an asymmetric battery supercapacitor configuration, the electrochemical extraction reactor does not store energy nor is the total $\mathrm{LiCl}$ concentration constant in the electrolyte. The extractor can use renewable solar energy to extract lithium with an overall change in $\mathrm{LiCl}$ electrolyte concentration, i.e. decrease during the extraction from brine (discharge) and increase during recovery (charge). ${ }^{32}$

We aim at a detailed understanding of the potential profiles and the distribution of ionic species within the packed bed reactor in order to efficiently design and scale up the reactor to achieve large scale operation. In this first work, we will assume a reactor where inhomogeneities occur only in the direction normal to the electrodes, $x$. The relevant variables in the model are the concentration of each ion, $c_{i}(x, t)$, the potential in the liquid electrolyte, $\varphi_{1}(x, t)$, the potential in the solid phase, $\varphi_{s}(\mathrm{x}, \mathrm{t})$ and the $\mathrm{Li}^{+}$ion concentration at the surface of the LMO particle, $\mathrm{c}_{\mathrm{Li}, \mathrm{s}}(\mathrm{x}, \mathrm{t})$. In the present work, we first validate our model by comparison of the experimental and simulated reactor voltage (voltage difference between current collectors), and then we analyze the concentrations and solid-electrolyte potential differences along the direction normal to the electrodes and separator $(x)$. The structure, porosity and thickness of the porous electrodes, concentration of brine and recovery electrolyte, current densities, etc. can be rationally studied in a one and two dimensional reactor including the flow of electrolyte in the latter case which will be described in future communications.

\section{Model of Reactor}

We have followed the work of Newman ${ }^{33-35}$ for the lithium ion battery electrode and the work of Hao for the asymmetric hybrid supercapacitor with LMO lithium intercalation electrode. ${ }^{28}$ The reactor consists of two porous packed bed electrodes separated by a porous insulating membrane filled with electrolyte. (See Scheme 1 and Figure S1 in SI) Both porous electrodes have current collectors and the electrolyte is fed from the base of the reactor at a constant flow rate with outflow on the top.

In this first approach, a one-dimensional model is considered which corresponds to an infinite two electrode system. We neglect the contribution from convection in this first part since this will be addressed in a future communication.

We will consider two operating configurations for the reactor. In both of them the LMO is a lithium insertion electrode. The second electrode can be:

a) A lithium adsorption carbon supercapacitor. This configuration will be analyzed for comparison with previously reported energy storage device by Hao. ${ }^{28}$ i.e. as a hybrid asymmetric super

\section{Positive electrode Negative electrode}

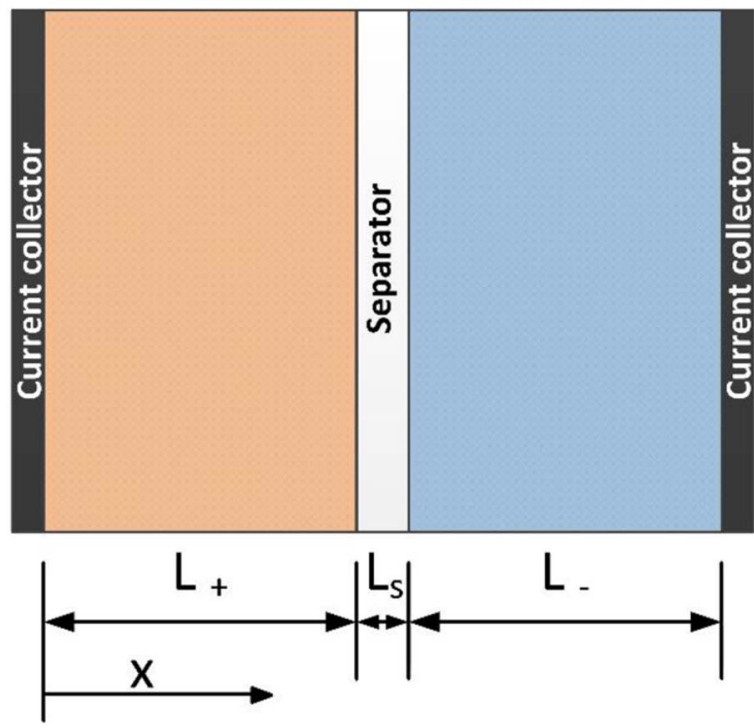

Scheme 1. Schematic representation of the reactor. Porous electrodes LMO $\left(0 \leq \mathrm{x} \leq \mathrm{L}_{+}\right)$, porous separator $\left(\mathrm{L}_{+} \leq \mathrm{x} \leq \mathrm{L}_{+}+\mathrm{L}_{\mathrm{s}}\right)$ and porous PPy $\left(\mathrm{L}_{+}+\right.$ $\left.\mathrm{L}_{\mathrm{s}} \leq \mathrm{x} \leq \mathrm{L}_{+}+\mathrm{L}_{\mathrm{s}}+\mathrm{L}\right)$

capacitor with a carbon double layer, or electrostatic capacitive electrode. This is also analogue to a lithium-ion battery with lithium insertion. ${ }^{36,37}$

b) A chloride selective PPy electrode: This configuration works as a lithium extraction/recovery device with an LMO lithium insertion electrode and a polypyrrole chloride selective pseudo-capacitive electrode.

The electrostatic potential of the solid conducting phase (coke) in the porous electrode is obtained from the charge balance using Ohm's law and the porous electrodes effective conductivities and diffusivities are calculated with the Bruggemann approximation. ${ }^{35}$ Here we should distinguish two solids: coke with particle size in the millimeter range and $\mathrm{LiMn}_{2} \mathrm{O}_{4}$ deposited on coke with average particle size in the nanometer range. In order to improve the electrical contact of LMO, it is necessary to support this active material on an inexpensive but stable material: coke using a PVDF binder and Vulcan carbon to improve
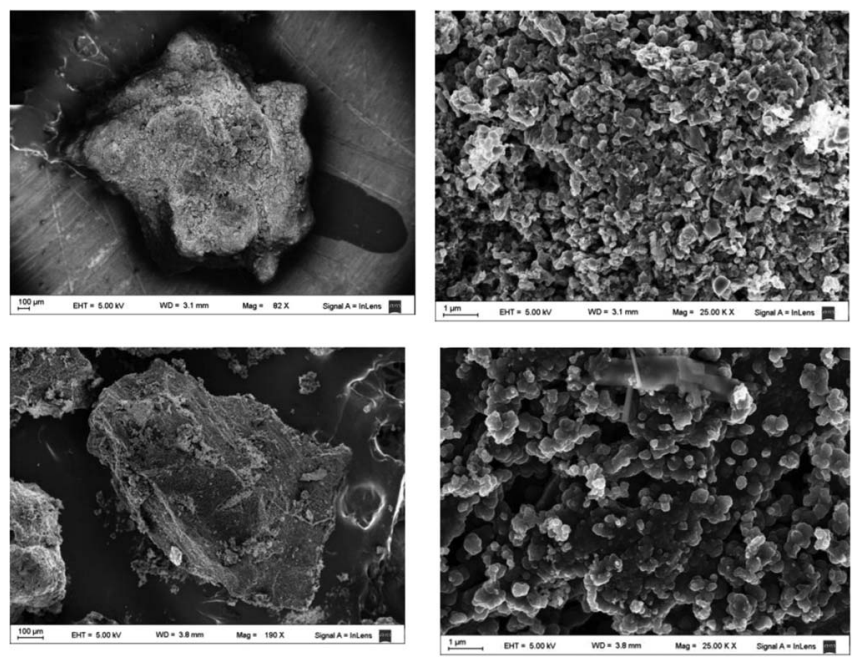

Figure 1. LMO covered particles (a), LMO crystals on coke particle (b), PPy deposit on coke (c), and detail of PPy deposit (d). 
the electrical contact. The solid volume fractions are respectively, $\varepsilon_{\text {coke }}$ for the large coke particle and $\varepsilon_{\mathrm{LMO}}$ for the smaller electroactive LMO particles deposited on coke particles. Figure 1 depicts a SEM image of LMO crystals deposited on a petroleum coke particle. It is of paramount importance to increase as much as possible the volume fraction of LMO, since the reaction stoichiometry defines the lithium insertion capacity of the reactor $38 \mathrm{mg} \mathrm{Li} / \mathrm{g} \mathrm{LMO}$ and the specific charge capacity $148 \mathrm{mAh} / \mathrm{g}$ LMO.

The ionic charge and mass balances in the electrolyte are obtained solving the Nernst-Planck equation for diffusion and migration of all participating ions combined with local electroneutrality (tertiary current distribution). This methodology is different with the previous treatment by Hao et al. for the binary lithium sulfate electrolyte in the asymmetric LMO/carbon supercapacitor, who used a model based on the secondary current distribution (which considers the current in the electrolyte through Ohm's law rather than the Nernst-Planck equation). ${ }^{28}$ Notice that the diffusion coefficient of $\mathrm{LiCl}$ in the electrolyte depends strongly on the $\mathrm{Li}^{+}$concentration, ${ }^{38}$ and on total brine salinity which has consequences in the concentration profiles as will be shown below.

The lithium ion diffusion within the $\mathrm{LiMn}_{2} \mathrm{O}_{4}$ spinel particles in the cathode material is described as a Fick diffusion process in spherical particles. The source and sink terms of electrical charge at the LMO-liquid interface are described by the Butler-Volmer equation for the lithium ion transfer at the solid-electrolyte interface. ${ }^{31}$

The simulations are run with a constant electrical current applied at the LMO positive electrode (left in Scheme 1) while the electrostatic potential at the rightmost end of the capacitive electrode (polypyrrole or carbon) is set to $0 \mathrm{~V}$ (right in Scheme 1). We consider a constant current, $\mathrm{I}_{\text {cell }}$, applied to the reactor from the left current collector (LMO), the current in the porous electrodes and separator is the sum of the electronic current in the solid phase of the porous electrode and the ionic current in the liquid electrolyte filling the porous matrix: ${ }^{34}$

$$
I_{\text {cell }}=i_{l}+i_{s}
$$

And thus,

$$
\nabla i_{l}=-\nabla i_{s}
$$

For the porous media we apply the Bruggeman condition to each species:

$$
D_{l, e f f}=\varepsilon_{l}^{1.5} D_{l} \quad \sigma_{s, \text { eff }}=\varepsilon_{s}^{1.5} \sigma_{s}
$$

where $\mathrm{D}_{\mathrm{i}}$ is the diffusion coefficient of the ion $\mathrm{i}$ in the liquid phase, $\sigma_{\mathrm{s}}$ is the conductivity in solid phase (LMO, carbon or polypyrrole) and $\varepsilon_{\mathrm{l}}$ and $\varepsilon_{\mathrm{s}}$ are the volume fractions of the liquid and solid phases respectively.

Capacitive electrode.-At the interface between the solid matrix and the electrolyte solution, the rate of change of the double layer (per unit volume of electrode) is given from Johnson and Newman: ${ }^{39}$

$$
q_{l o c}=S_{c a p} C_{c a p}\left(\varphi_{s}-\varphi_{l}\right)
$$

where $S_{\text {cap }}$ is the PPy or carbon electrode specific area $\left(\mathrm{m}^{-1}\right)$ and $\mathrm{q}_{\text {loc }}$ the local charge. $\mathrm{C}_{\text {cap }}$ the capacity in $\mathrm{F} / \mathrm{m}^{2}$.

The electronic current at the polypyrrole or carbon porous electrode is given by Ohm's law:

$$
i_{s}=-\sigma_{s, e f f} \frac{\partial \varphi_{s}}{\partial x}
$$

and, from the charge balance in the electrolyte, the local capacitor charging current per unit volume $\left(i_{v, c a p}\right.$ units of $\left.\mathrm{A} / \mathrm{m}^{3}\right){ }^{39}$

$$
i_{v, \text { cap }}=\frac{\partial i_{l}}{\partial x}=S_{\text {Cap }} C_{C a p} \frac{\partial\left(\varphi_{s}-\varphi_{l}\right)}{\partial t}
$$

due to charge conservation ${ }^{39}$ on the electrode with a capacitance $\mathrm{C}_{\mathrm{Cap}}$, $\left(\mathrm{F} / \mathrm{m}^{2}\right)$, and the interfacial specific area per unit volume $\mathrm{S}_{\mathrm{Cap}}\left(\mathrm{m}^{-1}\right)$. A typical capacitance of $550 \mathrm{~F} / \mathrm{g}$ has been reported for PPy. ${ }^{40}$
We therefore charge the capacitor by either: adsorbing $\mathrm{Li}^{+}$at the negatively charged carbon of a hybrid capacitive electrode. ${ }^{28,29,41}$ or, by exchanging selectively chloride anions at the poly-pyrrole electrode with the same current at which we intercalate (de-intercalate) lithium ions in the LMO electrode. ${ }^{26,27}$ The difference between these two processes is reflected in the stoichiometry coefficient of the source term in the mass balance equation (see below).

By differentiating Eq. 4 with respect to $\mathrm{x}$ and replacing in Eq. 5, with the condition in Eq. 2 we obtain the differential equation from which the electrical potential at each point can be determined.

$$
\nabla .\left(i_{s}\right)=-\sigma_{s, e f f} \frac{\partial^{2} \varphi_{s}}{\partial x^{2}}=S_{C a p} C_{C a p} \frac{\partial\left(\varphi_{l}-\varphi_{s}\right)}{\partial t}
$$

The ionic current at the electrolyte is given by the Nernst-Planck equation:

$$
i_{l}=F \sum_{i} z_{i}\left(-D_{i, e f f} \nabla c_{i}-\frac{z_{i} F D_{i, e f f} c_{i} \nabla \varphi_{l}}{R T}\right)
$$

where we used the Einstein-Smoluchowski relation for ion mobilities. In Equation 7, the sum runs over all the ions present in solution, e.g. for natural brine $\mathrm{i}=\mathrm{Li}^{+}, \mathrm{Na}^{+}, \mathrm{K}^{+}, \mathrm{Mg}^{+}, \mathrm{B}_{2} \mathrm{O}_{7}{ }^{2-}$ and $\mathrm{Cl}^{-}$. For the dilute $\mathrm{LiCl}$ recovery solution $\mathrm{i}=\mathrm{Li}^{+}, \mathrm{Cl}^{-}$and Eq. 7 can be simplified to:

$i_{l}=F\left(-D_{L i, e f f}+D_{C l, e f f}\right) \nabla c_{L i}-\frac{F^{2} \nabla \varphi_{l}}{R T}\left(D_{L i, e f f}+D_{C l, e f f}\right) c_{L i}$

(where the electroneutrality condition for a binary electrolyte $\mathrm{c}_{\mathrm{Li}+}=\mathrm{c}_{\mathrm{Cl}-}$ has been used). The first term on the right hand side is the diffusional flux due to the concentration gradient and the second one is the flux due to the electrical field. We neglect the convective term in this approach.

The mass balance in the electrolyte is given by:

$$
\varepsilon_{l} \frac{\partial c_{i}}{\partial t}=\nabla\left(D_{i, e f f} \nabla c_{i}+\frac{z_{i} D_{i, e f f} F c_{i} \nabla \varphi_{l}}{R T}\right)+R_{i}
$$

The source term is given by the source or sink of ions due to a faradaic intercalation reaction $R_{d l, i}=\frac{v_{i} i_{v, c a p}}{n F}$ and the stoichiometric coefficients, $\nu_{\mathrm{i}}$ for non-reactive ions are set to 0 .

At the porous separator.-There is no source or sink of ions, and the mass balance for multi-ion electrolyte, i.e. brine is:

$$
\frac{\partial c_{i}}{\partial t}=\nabla\left(D_{i, e f f} \nabla c_{i}+\frac{z_{i} D_{i, e f f} F c_{i} \nabla \varphi_{l}}{R T}\right) \text { and } \sum_{i} z_{i} c_{i}=0
$$

with the total ion current,

$$
i_{l}=F \sum_{i} z_{i}\left(-D_{i, e f f} \nabla c_{i}-\frac{z_{i} F D_{i, e f f} c_{i} \nabla \varphi_{l}}{R T}\right)
$$

Lithium Insertion electrode (LMO).-We follow the treatment of Newman $^{33,34}$ for the lithium ion insertion electrode at each LMO particle:

$$
\frac{\partial c_{S, i}}{\partial t}=D_{s}\left[\frac{\partial^{2} c_{S, i}}{\partial r^{2}}+\frac{2}{r} \frac{\partial c}{\partial r}\right] \quad 0 \leq r \leq r_{p}
$$

With the boundary conditions at each particle:

$$
\left.\frac{\partial c_{s}}{\partial r}\right]_{r=0}=0
$$

and,

$$
\left.-D_{s} \frac{\partial c_{s}}{\partial r}\right]_{r=r_{p}}=R_{L i, \theta}=\frac{\nu_{L i_{\theta}} \cdot i_{v}}{F} \frac{r_{p}}{3 \varepsilon_{L M O}}
$$

where, $r_{p}$ is the LMO particle radius, $\nu_{\mathrm{Li}, \theta}$ is the stoichiometric coefficient for $\mathrm{Li}^{+}$at the particle surface (see below) and $\mathrm{i}_{\mathrm{v}}$ is the volume 
faradaic current density defined as $i_{v}=i_{\text {loc }} S_{f}$, where $S_{f}$ is the specific electroactive area of the particles (unit $\mathrm{m}^{-1}$ ) and $\mathrm{i}_{\text {loc }}$ is the local faradaic current given by Butler-Volmer equation (see below).

The $\mathrm{LiMn}_{2} \mathrm{O}_{4}$ electrode volume fraction, $\varepsilon_{\mathrm{LMO}}$, is given by: ${ }^{42}$

$$
\varepsilon_{L M O}=\frac{Q_{L M O}}{\Delta s o c . c_{s, \text { max }} F . l}
$$

$\Delta$ soc is the allowed state-of-charge $\left(\operatorname{soc}=\mathrm{c}_{\mathrm{s}} / \mathrm{c}_{\mathrm{s}, \max }\right)$ window of LMO, $\mathrm{c}_{\mathrm{s}, \max }=25 \mathrm{M}$ for $\mathrm{LMO}^{33}$ and the porous electrode thickness, $l$.

The current in the solid electrode is given by:

$$
i_{s}=-\sigma_{s, e f f} \frac{\partial \phi_{s}}{\partial \mathrm{x}}
$$

and, the overpotential at each position by: $\eta=\phi_{s}-\phi_{l}-\Delta \phi_{s, \text { film }}-E_{e q}$.

The equilibrium potential of $\mathrm{LiMn}_{2} \mathrm{O}_{4}$ in aqueous $\mathrm{LiCl}, \mathrm{E}_{\mathrm{eq}}$ is determined both by the oxide composition ( $\mathrm{x}$ in $\mathrm{Li}_{1-\mathrm{x}} \mathrm{Mn}_{2} \mathrm{O}_{4}$ ) and the $\mathrm{LiCl}$ activity in natural brine or in diluted $\mathrm{LiCl}$ aqueous solution. ${ }^{30}$ Notice that $E_{e q}$, for each state of charge (soc) has been determined independently by charging an LMO electrode at very low current density as shown in Figures S2 and S3 the SI for $0.05 \mathrm{M} \mathrm{LiCl}$ and natural brine. Therefore, the extrapolation curve used by the model must be that of the electrolyte being employed in extraction from brine or recovery of $\mathrm{LiCl}$ dilute solution respectively.

The ohmic drop in the LMO films, equal to $\Delta \phi_{s, f i l m}=R_{\text {film }} . I_{\text {total }}$, is negligible in our model.

The Butler-Volmer equation for the local faradaic current density $\mathrm{i}_{\text {loc }}: 31$

$$
i_{l o c}=F k_{0}^{0}(1-\theta)^{\alpha_{a}}(\theta)^{\alpha_{c}}\left(\frac{c_{L i}}{c_{L i, r e f}}\right)^{\alpha_{a}}
$$

with $\mathrm{c}_{\mathrm{s}} / \mathrm{c}_{\mathrm{s}, \max }=\theta, k_{0}^{0}=k_{c}^{\alpha_{a}} k_{a}^{\alpha_{c}} c_{s, \max }^{\left(\alpha_{a}+\alpha_{c}\right)}$, the reference lithium concentration $c_{\text {Li,ref }}=1 \mathrm{~mol} . \mathrm{m}^{-3}$ and $\alpha_{\mathrm{a}}=\alpha_{\mathrm{c}}=0.5$

The current in the electrolyte is:

$$
i_{l}=F \sum_{i} z_{i}\left(-D_{i, e f f} \nabla c_{i}-\frac{z_{i} F D_{i, e f f} c_{i} \nabla \varphi_{l}}{R T}\right)
$$

For the recovery solution $\left(\mathrm{i}=\mathrm{Li}^{+}\right.$and $\left.\mathrm{Cl}^{-}\right)$or brine $\left(\mathrm{i}=\mathrm{Li}^{+}, \mathrm{Na}^{+}\right.$, $\mathrm{K}^{+}, \mathrm{Mg}^{2+}, \mathrm{B}_{2} \mathrm{O}_{7}{ }^{2-}$ and $\mathrm{Cl}^{-}$).

The mass balance is given by:

$$
\varepsilon_{l} \frac{\partial c_{i}}{\partial t}=\nabla\left(D_{i, e f f} \nabla c_{i}+\frac{z_{i} D_{i, e f f} F c_{i} \nabla \varphi_{l}}{R T}\right)+R_{i}
$$

with $R_{i}=\frac{v_{i} i_{v}}{n F}$. The stoichiometric coefficients for non-reactive ions are set to 0 . We impose the use the electroneutrality condition $\sum_{i} z_{i} c_{i}=0$

\section{Boundary Conditions}

At $t=0$ :

At the Ppy or carbon electrode $\left(L_{+}+L_{\mathrm{S}}<x<L_{+}+L_{\mathrm{S}}+L_{-}\right)$

$$
\phi_{s}=\phi_{l}=0
$$

At the separator $\left(L_{+}<x<L_{+}+L_{S}\right)$

$$
\phi_{l}=0
$$

At the $\mathrm{LMO}\left(0 \leq \mathrm{x}<\mathrm{L}_{+}\right)$

$$
\phi_{l}=0 \quad \phi_{s}=E_{e q}\left(\frac{c_{S .0}}{C_{S . \max }}\right)
$$

$t>0$

at $x=0$

$\frac{\partial c_{i}}{\partial x}=0, \mathrm{i}_{\mathrm{l}}=0, \mathrm{i}_{\mathrm{S}}=\mathrm{I}_{\text {cell }}$

at $\mathrm{x}=L_{+}$and $x=L_{+}+L_{\mathrm{S}}$

$\mathrm{i}_{\mathrm{S}}=0, \frac{\partial i_{l}}{\partial x}=0$

at $x=L_{+}+L_{\mathrm{s}}+L_{-}$

$\frac{\partial c_{i}}{\partial x}=0, \mathrm{i}_{1}=0, \mathrm{i}_{\mathrm{S}}=\mathrm{I}_{\text {cell }}, \phi_{S}=0$ (choice of the zero of electrostatic potential)

\section{Table I. Stoichiometric Coefficients.}

\begin{tabular}{lccc} 
& $\nu_{\mathrm{Li}+}$ & $\nu_{\mathrm{Cl}-}$ & $\begin{array}{c}\nu_{\mathrm{Li} \theta+} \text { (ion in } \\
\text { LMO Particles) }\end{array}$ \\
\hline LMO & -1 & 0 & 1 \\
PPy & 0 & 1 & 0 \\
Carbon & -1 & 0 & 0
\end{tabular}

The stoichiometric coefficient, $v_{i}$, defines which species are inserted from or into the electrode or delivered into the electrolyte at the LMO/electrolyte, PPy/electrolyte or carbon/electrolyte inter-faces during a reduction process:

$$
\sum_{o x}\left|v_{o x}\right| O x+n e=\sum_{r e d} v_{\text {red }} \text { Red }
$$

With $v_{\text {red }}>0$ and $v_{\text {ox }}<0$. Note that the coefficients of Eq. 20 are defined for a reduction process in a given electrode. The sign of the applied current determines the type of process occurring in each electrode. For $I_{\text {cell }}>0$ occurs the delithiation process, which produces the oxidation of the LMO electrode and the reduction of the PPy or carbon electrode. For $I_{\text {cell }}<0$ occurs the lithium insertion (reduction of LMO and oxidation of PPy or carbon). Table I summarizes the stoichiometric coefficients used in the simulations.

\section{Simulation}

COMSOL Multiphysics 5.2a was used to implement the simulations. A multiscale simulation was performed using the lithium-ion battery module for the diffusion in the LMO particles and the tertiary current distribution module for the transport of the electrolyte species. ${ }^{42}$ The current implementation of the battery model in Comsol 5.2a uses secondary current distribution instead of tertiary current distribution. In order to use the intercalation model (i.e. diffusion of $\mathrm{Li}$ in LMO particles) with the tertiary current distribution, we set both a Battery Module (lion) and a Tertiary Distribution Module (tcdee) in the LMO region. We then used the Battery Module to solve the diffusion of Li within the LMO particles and the Tertiary Current Distribution Module to solve the ion transport in solution and the Butler-Volmer equation at the LMO/electrolyte interfase. To do so, the lithium concentration at the surface of LMO particles (lion.cs_surface) was used as an input for the Butler-Volmer equation in the Tertiary Current Distribution Module (see Eq. 17) and the local current density of the Tertiary Current Distribution Module (tcdee.iloc_per1) was used as an input in the Battery Module for calculating the flux of $\mathrm{Li}$ ions at the surface of the LMO particles (see Eq. 14). This strategy was validated by comparison of the solution of the asymmetric supercapacitor with a binary lithium electrolyte provided by the Battery Module (i.e. Secondary Current Distribution) and provided by our approach (Tertiary Current Distribution), see Fig. S4 of SI. The small differences between both solutions are attributed to the fact that the secondary current distribution uses the conductivity of the electrolyte as an input, while the tertiary current distribution uses the diffusion coefficients of the ions.

Table II summarizes the description and the numerical values used for all parameters in the simulations, including the reference from where these values where extracted, where appropriate.

\section{Experimental}

In the experimental work an electrochemical rectangular channel filter-press reactor (type FM01-LC) ${ }^{45-47}$ with two packed bed electrodes of $15.5 \times 4.5 \times 0.5 \mathrm{~cm}\left(69.75 \mathrm{~cm}^{2}\right.$ area $)$ in PTFE body, 304 stainless steel current collectors separated by a $200 \mu \mathrm{m}$ thick porous polyethylene battery separator (Daramic HP) with $60 \%$ porosity and $55 \mathrm{~m} \Omega \cdot \mathrm{cm}^{-2}$.

The electrolytes employed were natural brine from Olaroz salt flat, Jujuy (Argentina) with a composition analyzed by ICP-OES (SPECTRO Modula Flame): $\mathrm{Na}^{+} 115.600 \mathrm{ppm}(5 \mathrm{M} \mathrm{NaCl}), \mathrm{K}^{+}$ 10.780 ppm $(0.28 \mathrm{M} \mathrm{KCl}), \mathrm{Mg}^{2+} 2.618 \mathrm{ppm}, \mathrm{Li}^{+}$975-1280 ppm 
Table II. Parameters used in the simulation of reactor.

\begin{tabular}{|c|c|c|c|}
\hline Parameter & Description & Value & Ref. \\
\hline $\mathrm{L}_{+}$ & Thickness of positive electrode (LMO), $\mathrm{cm}$ & 0.5 & \\
\hline $\mathrm{L}_{-}$ & Thickness of negative electrode (PPy), cm & 0.5 & \\
\hline $\mathrm{L}_{\mathrm{s}}$ & Thickness of porous separator, $\mathrm{cm}$ & 0.1 & \\
\hline $\mathrm{C}_{\mathrm{PPy}}$ & Capacitance of $\mathrm{PPy}, \mathrm{F} / \mathrm{m}^{2}$ & $4.2 \times 10^{4}$ & \\
\hline $\mathrm{S}_{\mathrm{PPy}}$ & Specific surface area of PPy per unit electrode volume, $\mathrm{m}^{-1}$ & 100 & \\
\hline $\mathrm{S}_{\mathrm{LMO}}$ & Specific surface area of LMO per unit electrode volume, $\mathrm{m}^{-1}$ & $5 \times 10^{6}$ & \\
\hline $\mathrm{D}_{\mathrm{Li}^{+}}$ & Diffusion coefficient of $\mathrm{Li}^{+}$in solid phase, $\mathrm{m}^{2} / \mathrm{s}$ & $6 \times 10^{-14}$ & 26 \\
\hline $\mathrm{D}_{\mathrm{Li}^{+}}^{\mathrm{Li}}$ & Diffusion coefficient of $\mathrm{Li}^{+}$in $\mathrm{LiCl}$ electrolyte, $\mathrm{m}^{2} / \mathrm{s}$ & $9.9 \times 10^{-10}$ & 43 \\
\hline $\mathrm{D}_{\mathrm{Li}^{+}}$ & Diffusion coefficient of $\mathrm{Li}^{+}$in natural brine, $\mathrm{m}^{2} / \mathrm{s}$ & $9.62 \times 10^{-10}$ & 43 \\
\hline $\mathrm{D}_{\mathrm{Cl}^{-}}$ & Diffusion coefficient of $\mathrm{Cl}^{-}$in $\mathrm{LiCl}$ electrolyte, $\mathrm{m}^{2} / \mathrm{s}$ & $1.98 \times 10^{-9}$ & 43 \\
\hline $\mathrm{D}_{\mathrm{Cl}^{-}}$ & Diffusion coefficient of $\mathrm{Cl}^{-}$in $\mathrm{LiCl}$ natural brine, $\mathrm{m}^{2} / \mathrm{s}$ & $1.86 \times 10^{-9}$ & 44 \\
\hline $\mathrm{D}_{\mathrm{Na}^{+}}$ & Diffusion coefficient of $\mathrm{Na}^{+}$in natural brine, $\mathrm{m}^{2} / \mathrm{s}$ & $13.4 \times 10^{-10}$ & 44 \\
\hline $\mathrm{D}_{\mathrm{K}^{+}}$ & Diffusion coefficient of $\mathrm{K}^{+}$in natural brine, $\mathrm{m}^{2} / \mathrm{s}$ & $17.9 \times 10^{-10}$ & 44 \\
\hline $\mathrm{D}_{\mathrm{Mg}^{++}}$ & Diffusion coefficient of $\mathrm{Mg}^{2+}$ in natural brine, $\mathrm{m}^{2} / \mathrm{s}$ & $7.5 \times 10^{-10}$ & 44 \\
\hline $\mathrm{D}_{\mathrm{B} 2 \mathrm{O} 7}{ }^{2-}$ & Diffusion coefficient $\mathrm{B}_{2} \mathrm{O}_{7}{ }^{2-}$ in natural brine, $\mathrm{m}^{2} / \mathrm{s}$ & $1 \times 10^{-10}$ & \\
\hline$\varepsilon_{l}$ & Volume fraction of liquid phase & 0.50 & \\
\hline$\varepsilon_{s}$ & Volume fraction of solid phase, coke & 0.50 & \\
\hline $\mathrm{c}_{l, \mathrm{LiCl}}$ & Initial concentration of $\mathrm{Li}^{+}$in $\mathrm{LiCl}$ electrolyte, $\mathrm{mol} / \mathrm{m}^{3}$ & 0.05 & \\
\hline $\mathrm{c}_{\mathrm{s}, \mathrm{Li}+, \mathrm{lit}}$ & Initial concentration of $\mathrm{Li}^{+}$in solid (litiation), $\mathrm{mol} / \mathrm{m}^{3}$ & 1000 & \\
\hline $\mathrm{c}_{\mathrm{S}, \mathrm{Li}+, \mathrm{del}}$ & Initial concentration of $\mathrm{Li}^{+}$in solid (delitiation), $\mathrm{mol} / \mathrm{m}^{-3}$ & 25000 & \\
\hline $\mathrm{C}_{\mathrm{Li}^{+}}$ & Initial concentration of $\mathrm{Li}^{+}$in natural brine, $\mathrm{mol} / \mathrm{m}^{3}$ & 200 & 27 \\
\hline $\mathrm{c}_{\mathrm{Na}^{+}}+$ & Initial concentration of $\mathrm{Na}^{+}$in natural brine, $\mathrm{mol} / \mathrm{m}^{3}$ & 5000 & 27 \\
\hline $\mathrm{c}_{\mathrm{K}^{+}}$ & Initial concentration of $\mathrm{K}^{+}$in natural brine, $\mathrm{mol} / \mathrm{m}^{3}$ & 280 & 27 \\
\hline $\mathrm{c}_{\mathrm{Mg}^{2+}}$ & Initial concentration of $\mathrm{Mg}^{2+}$ in natural brine, $\mathrm{mol} / \mathrm{m}^{3}$ & 100 & 27 \\
\hline $\mathrm{c}_{\mathrm{B} 2 \mathrm{O} 7^{2-}}$ & Initial concentration of $\mathrm{B}_{2} \mathrm{O}_{7}{ }^{2-}$ in natural brine, $\mathrm{mol} / \mathrm{m}^{3}$ & 9 & 27 \\
\hline $\mathrm{C}_{\mathrm{Cl}^{-}}$ & Initial concentration of $\mathrm{Cl}^{-}$in natural brine, $\mathrm{mol} / \mathrm{m}^{3}$ & 5662 & 27 \\
\hline $\mathrm{c}_{\mathrm{s}, \max }$ & Maximum concentration of $\mathrm{Li}^{+}$in solid, $\mathrm{mol} / \mathrm{m}^{3}$ & 25000 & \\
\hline$\alpha_{\mathrm{c}}=\alpha_{\mathrm{a}}$ & Anodic and cathodic faradaic transfer coefficient & 0.5 & 34 \\
\hline$r_{p}$ & LMO particle radius, $\mathrm{nm}$ & 100 & \\
\hline $\mathrm{r}_{\mathrm{PPY}}$ & PPy particle radius, $\mu \mathrm{m}$ & $400-1000$ & \\
\hline$\sigma_{1}$ & Conductivity of natural brine electrolyte, $\mathrm{S} / \mathrm{m}$ & 17.35 & 27 \\
\hline$\sigma_{\mathrm{s}, \mathrm{pos}}$ & Conductivity in solid phase positive electrode, $\mathrm{S} / \mathrm{m}$ & 3.8 & \\
\hline$\sigma_{\mathrm{S}, \mathrm{neg}}$ & Conductivity in solid phase negative electrode, $\mathrm{S} / \mathrm{m}$ & 10 & \\
\hline $\mathrm{k}_{\mathrm{c}}=\mathrm{k}_{\mathrm{a}}$ & Specific rate constant of faradaic Reaction, $\mathrm{m} / \mathrm{s}$ & $10^{-11}$ & \\
\hline $\mathrm{c}_{l, \mathrm{ref}}$ & Electrolyte reference concentration, $\mathrm{mol} / \mathrm{m}^{3}$ & 1 & \\
\hline$\Delta$ soc & Allowed state-of-charge & 1 & \\
\hline $\mathrm{F}$ & Faraday constant, C/equiv & 96,484 & \\
\hline $\mathrm{R}$ & Universal gas constant, $\mathrm{J} / \mathrm{mol} . \mathrm{K}$ & 8.314 & \\
\hline $\mathrm{T}$ & Absolute temperature, $\mathrm{K}$ & 298 & \\
\hline
\end{tabular}

(0.18 M LiCl), Boron 1.440 ppm. The natural brine had a dynamic viscosity $2.077 \mathrm{Cp}$, a density of $1.2710 \mathrm{~g} . \mathrm{cm}^{-3}$ and an electrical conductivity of $0.1735{\mathrm{~S} . \mathrm{cm}^{-1}}^{27}$ The recovery electrolyte was $0.05 \mathrm{M} \mathrm{LiCl}$ solution.

The electrolyte was circulated through the reactor by a rotary pump resistant to high concentrated electrolyte and the electrolysis reactor was operated at constant current controlled by an Autolab 30 potentiostat/galvanostat. The open circuit potential of the LMO electrode with respect to $\mathrm{Ag} / \mathrm{AgCl} ; 3 \mathrm{M} \mathrm{NaCl}(0.22 \mathrm{~V}$ vs. NHE) reference electrode defined the initial state of charge (soc LMO). All chemical reagents where of analytical grade, except for Coke provided by Copetro.

The properties of the packed bed electrodes were determined as follows: The volume fraction of electrolyte was determined from the mass and volume of the packed coke particles. The density of the coke particles was determined with a $25 \mathrm{~mL}$ pycnometer.

The LMO electrode was prepared from a slurry of $\mathrm{LiMn}_{2} \mathrm{O}_{4}(80 \%)$, $10 \%$ PVDF and 10\% Vulcan Carbon XR-72 (Cabot Corp.) dispersed in N-methyl pyrrolidone onto coke particles (ASTM mesh 35) and dried at $105^{\circ} \mathrm{C}$. The loading of electroactive LMO was determined by differential weighing.

The PPy electrode was prepared by polymerization on coke particles using $100 \mathrm{~mL}$ of $0.5 \mathrm{M}$ pyrrole in $0.02 \mathrm{M} \mathrm{HCl}$ by adding an equal volume of $\mathrm{FeCl}_{3}$ with vigorous stirring during 15 minutes. After separating the supernatant liquid and rinsing with water the material was dried at $110^{\circ} \mathrm{C}$.
After operating the reactor with natural brine, the reactor was rinsed with 2.5-3 liters of distilled water for a $35 \mathrm{~cm}^{3}$ electrolyte volume in the packed bed electrodes until no chloride could be detected in the rinsing water by silver nitrate.

\section{Results and Discussion}

We start by describing the reactor using PPy capacitive electrode and LMO intercalation electrode.

In the electrochemical reactor the process at each porous electrode produces the separation of $\mathrm{Li}^{+}$and $\mathrm{Cl}^{-}$ions by the selective intercalation at the $\mathrm{LiMn}_{2} \mathrm{O}_{4}$ electrode and the capacitive PPy electrode. This is similar to the reported $\mathrm{LiMn}_{2} \mathrm{O}_{4}$ hybrid supercapacitor with activated carbon as capacitive electrode. ${ }^{28}$

There are, however several differences between a hybrid $\mathrm{LiMn}_{2} \mathrm{O}_{4} /$ carbon supercapacitor and the present lithium chloride extraction reactor: a): the thickness of the porous electrodes in the first case is of a few hundred micrometers only, in our specific reactor the porous electrode thickness is in centimeters range, and therefore the mass of active materials is much larger, b) the lithium salt concentration in a battery or in a hybrid super capacitor is very high in the $1 \mathrm{M}$ range, but natural brine contains only $0.1-0.2 \mathrm{M} \mathrm{LiCl}, \mathrm{c}$ ) the electrochemical reactor to extract lithium operates in two steps with two different electrolytes, brine and dilute $\mathrm{LiCl}$ recovery aqueous solution respectively, while the supercapacitor contains a single electrolyte in 
$\mathrm{t}(\mathrm{s})$

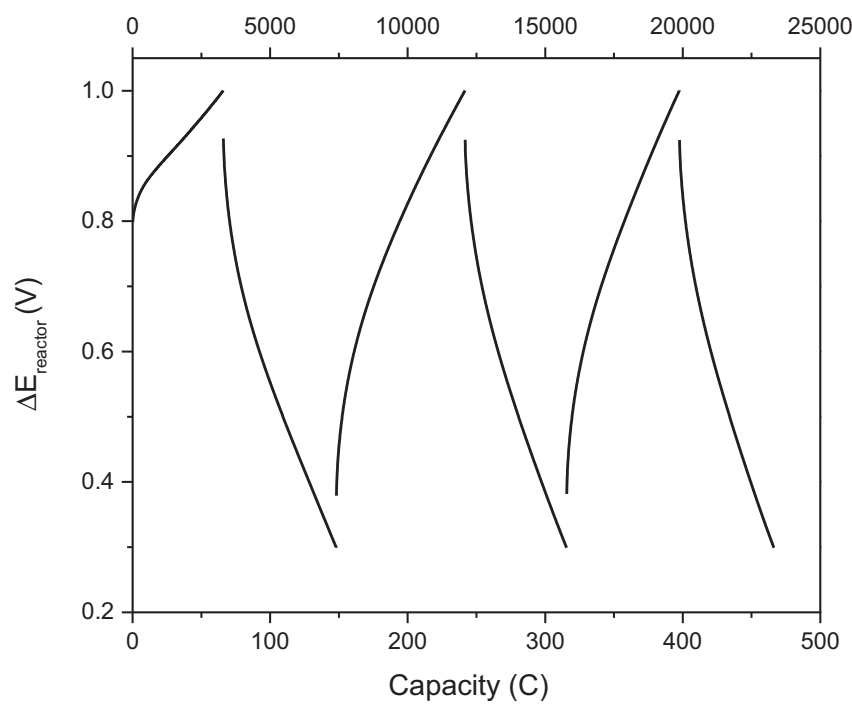

Figure 2. Experimental charge-discharge curves during delithiation and lithium intercalation respectively at $20 \mathrm{~mA}\left(0.29 \mathrm{~mA} . \mathrm{cm}^{-2}\right)$ of LMO-PPy reactor in $0.05 \mathrm{M} \mathrm{LiCl} . \mathrm{R}_{\mathrm{u}}=3.6 \Omega . \mathrm{m}_{\mathrm{LMO}}=9.90 \mathrm{~g}, \mathrm{~m}_{\text {PPy }}=6.43 \mathrm{~g}$.

non-aqueous solvent. Lithium ion in aqueous electrolyte under the conditions of the reactor has a transport number less than unity, and the ion transport is an important factor. The diffusion coefficient of $\mathrm{Li}^{+}$ions is concentration dependent, i.e. $\mathrm{Li}^{+}$and $\mathrm{Cl}^{-}$have similar diffusivities in concentrated solutions (brine) but $\mathrm{D}_{\mathrm{Li}+}$ is half the value of $\mathrm{D}_{\mathrm{Cl}}$ in very dilute solutions. This has important consequences in the $\mathrm{LiCl}$ concentration distribution in the electrolyte with asymmetry in both porous electrodes.

In addition to $\mathrm{LiCl}$, natural brine contains other ions such as $\mathrm{Na}^{+}$, $\mathrm{K}^{+}, \mathrm{Mg}^{2+}, \mathrm{Cl}^{-}, \mathrm{SO}_{4}{ }^{2-} \mathrm{B}_{2} \mathrm{O}_{7}{ }^{2-}$ etc. Most of these ions are present in concentrations much larger than $\mathrm{Li}^{+}$, particularly $\mathrm{NaCl}$ is usually present at concentrations between 3-5 M. These ions diffuse and migrate during the charge-discharge of the reactor which introduces the need for solving the Nernst-Planck transport conditions for all ions present in the simulation.

Another important difference is that a lithium battery or a hybrid supercapacitor stores electrical charge at constant total concentration, while in the reactor $\mathrm{LiCl}$ concentration changes during charge and discharge.

The experimental $\mathrm{LiCl}$ release (charge) and extraction (discharge) curves for the reactor in $50 \mathrm{mM} \mathrm{LiCl}$ electrolyte at $20 \mathrm{~mA}$ $\left(0.29 \mathrm{~mA} . \mathrm{cm}^{-2}\right)$ are shown in Figure 2 . The total voltage at the reactor current collectors $\Delta \mathrm{E}_{\text {reactor }}$ grows during anodic release of $\mathrm{LiCl}$ into the electrolyte and decreases during the extraction step as expected.

The average uncompensated internal resistance of the reactor has been calculated from the potential difference at the end of the charging curve and at the beginning of the discharge curve divided by the applied constant current. The ohmic drop in the reactor includes the electrolyte resistance and the contact resistance of the solid conducting material, and can be estimated in $R_{u}=3.6 \Omega$ for the experiment depicted in Figure 2. During the operation of the reactor, the potentials were restricted between 0.3 and $1.0 \mathrm{~V}$ cutoff values in order to keep the stoichiometry in the cubic phase $\mathrm{Li}_{\mathrm{x}} \mathrm{Mn}_{2} \mathrm{O}_{4}$ with $0 \leq \mathrm{x} \leq 1 .{ }^{27}$

In order to compare the simulated and the experimental full reactor potential, the $\mathrm{LiMn}_{2} \mathrm{O}_{4}$ equilibrium potential used by the simulation has been referred to the $\mathrm{Ag} / \mathrm{AgCl}$ reference electrode while the PPy electrode is set $0 \mathrm{~V}$ initially at zero charge. Therefore, the equilibrium potential of LMO has been subtracted from the potential of uncharged $\mathrm{PPy}$ in the $\mathrm{Ag} / \mathrm{AgCl}$ scale to ensure the same reference potential in both electrodes.

The experimental galvanostatic transients shown in Figure 2 are qualitatively similar to those reported for the $\mathrm{LiMn}_{2} \mathrm{O}_{4} /$ activated $\mathrm{t}(\mathrm{s})$

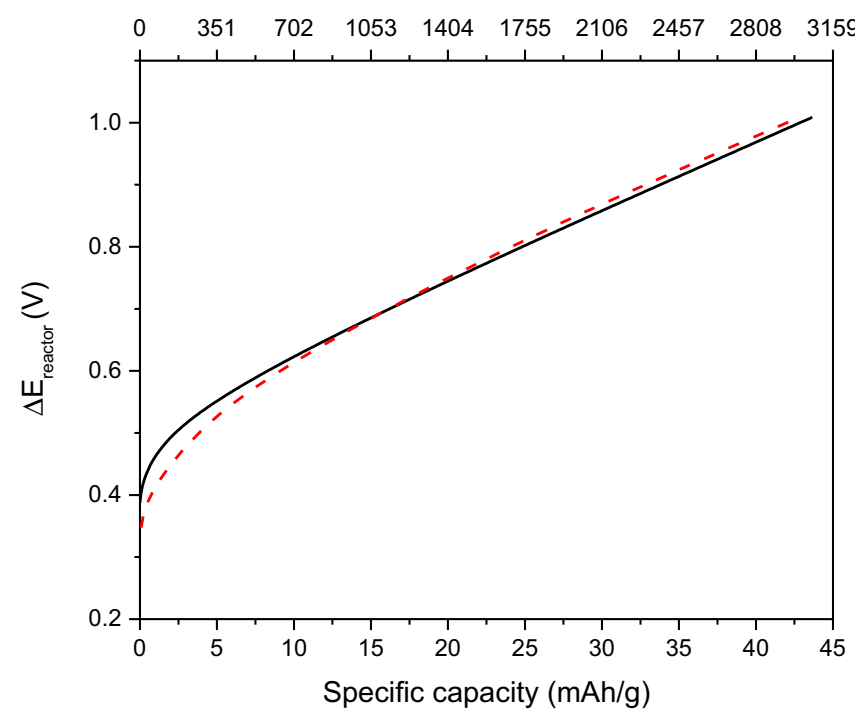

Figure 3. Experimental de-lithiation (charge) curve of $\mathrm{LiMn}_{2} \mathrm{O}_{4}$ anode and PPy cathode reactor at $20 \mathrm{~mA}\left(0.29 \mathrm{~mA} . \mathrm{cm}^{-2}\right)$ in $0.05 \mathrm{M} \mathrm{LiCl}$ (solid line), and simulated curve for $\mathrm{C}_{\mathrm{PPy}}=4.2 \mathrm{~F} / \mathrm{cm}^{2}, \varepsilon_{\mathrm{LMO}}=0.0025$ (dashed line).

carbon hybrid supercapacitor. ${ }^{28,29}$ Notice that the two-plateau typical of $\mathrm{Li}_{\mathrm{x}} \mathrm{Mn}_{2} \mathrm{O}_{4}$ intercalation in the $0 \leq \mathrm{x} \leq 1$ stoichiometry (see Figures S2 and S3 in SI) ${ }^{48-50}$ cannot be seen since the charging curves in these experiments are limited by the PPy charging (see below)

The simulation was validated by comparison with the experimentally observed $\Delta \mathrm{E}_{\text {reactor }} \mathrm{vs}$. time (or charge at constant current) in Figures 3 and 4.

Because it is experimentally much easier to synthesize $\mathrm{LiMn}_{2} \mathrm{O}_{4}$ which can undergo a topotatic transformation to $\mathrm{Li}_{1-x} \mathrm{Mn}_{2} \mathrm{O}_{4}$ (with $\mathrm{x} \rightarrow 1$ ), the first step is always the electrochemical delithiation of the LMO electrode, i.e. charging as the first step.

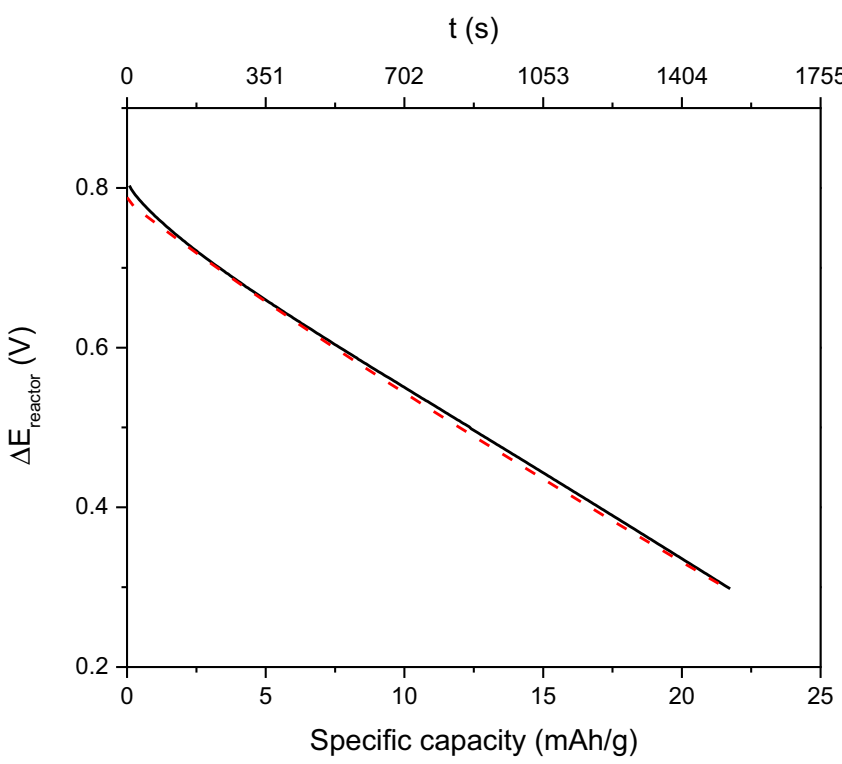

Figure 4. Experimental lithiation (discharge) curve of $\mathrm{Li}_{1-\mathrm{x}} \mathrm{Mn}_{2} \mathrm{O}_{4}(\theta=0.04)$ cathode and PPy anode reactor at $20 \mathrm{~mA}\left(0.29 \mathrm{~mA} \cdot \mathrm{cm}^{-2}\right)$ in natural brine after delithiation in $0.05 \mathrm{M} \mathrm{LiCl}$ (solid line) and simulated curve for $\mathrm{C}_{\mathrm{PPy}}=2.2 \mathrm{~F} / \mathrm{cm}^{2}, \varepsilon_{\mathrm{LMO}}=0.0025$ (dashed line). 


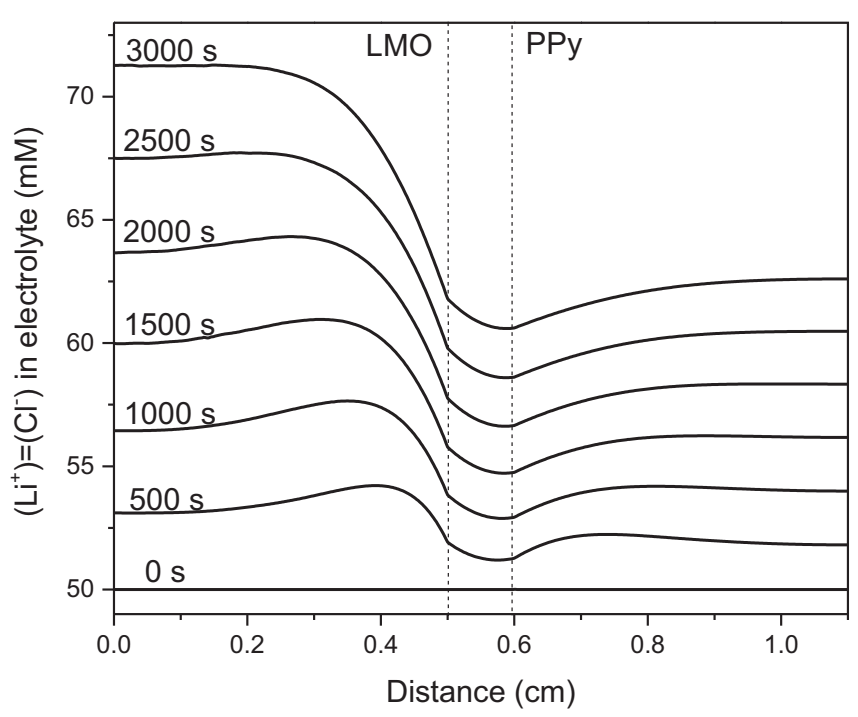

Figure 5. Concentration profiles of $\left[\mathrm{Li}^{+}\right]=\left[\mathrm{Cl}^{-}\right]$in the binary electrolyte along the distance in the 1D reactor for data in Fig. 3, $0.05 \mathrm{M} \mathrm{LiCl}$ and $20 \mathrm{~mA}$.

Figure 3 depicts an experimental charging curve of $\mathrm{LiMn}_{2} \mathrm{O}_{4}$ and $\mathrm{PPy}$ in the reactor at $20 \mathrm{~mA}$ constant current by releasing lithium chloride to a $50 \mathrm{mM} \mathrm{LiCl}$ recovery electrolyte (solid line) and the simulated curve for $\mathrm{C}_{\mathrm{PPy}}=4.2 \mathrm{~F} . \mathrm{cm}^{-2}$ and $\varepsilon_{\mathrm{LMO}}=0.0025$ (dashed line) with good fit. The small discrepancy between the model and the experimental results at short times may be due to a slight difference in the initial state of charge of the LMO electrode, i.e. $\mathrm{Li}_{\mathrm{x}} \mathrm{Mn}_{2} \mathrm{O}_{4}$ with $\mathrm{x}$ slightly less than 1 .

Based on the molecular structure of the tetramer $\mathrm{PPy}^{+}$cation and chloride anion, the theoretical charge capacity of $\mathrm{PPy}^{+} \mathrm{Cl}^{-}$is $92 \mathrm{mAh} / \mathrm{g}$ PPy while the charge capacity of $\mathrm{LiMn}_{2} \mathrm{O}_{4}$ is $148 \mathrm{mAh} / \mathrm{g}$ LMO. Therefore, if the mass ratio of PPy to LMO is less than $2: 1$ the potential of the reactor is determined by the linear charging curve of PPy and reaches the cutoff potentials in the first intercalation wave, reaching only $40 \mathrm{mAh} / \mathrm{g}$ LMO much less than expected. This limitation is illustrated in a plot of the individual solid-electrolyte potential evolution for PPy and LMO respectively in the extremes of the reactor (see Figure S5 in SI) with the main contribution to the total reactor voltage given by the charging of the capacitive PPy electrode, as reported for the LMO/Carbon supercapacitor. ${ }^{29}$ Also the simulated $\Delta \mathrm{E}_{\text {reactor }}$ charging curves for different mass ratios LMO to PPy shown in Figure S6 in SI confirm the limitations by the PPy capacitor charging current.

After full charge of the reactor, the $3 \mathrm{D}$ porous electrodes and the separator were washed by circulating water and the electrolyte was replaced with natural brine to capture lithium by intercalation into $\mathrm{Li}_{1-\mathrm{x}} \mathrm{Mn}_{2} \mathrm{O}_{4}$, (with $\mathrm{x} \rightarrow 1$ ) at $20 \mathrm{~mA}$ and the resulting time evolution of $\Delta \mathrm{E}_{\text {reactor }}$ is depicted in Figure 4 (solid line) together with the simulated curve for $\mathrm{C}_{\mathrm{PPy}}=2.2 \mathrm{~F}_{\mathrm{cm}} \mathrm{cm}^{-2}$ and $\varepsilon_{\mathrm{LMO}}=0.0025$ (dashed line) with good agreement between experiment and simulation. Notice that, except for a small decrease in $\mathrm{C}_{\mathrm{PPy}}$ both capture and recovery curves were fit with the same parameters.

Based on the results of the simulation the $\mathrm{Li}^{+}$and $\mathrm{Cl}^{-}$ion concentration profiles across the reactor thickness were calculated as shown in Figure 5 and Figure 6 for data in Figure 3 (binary LiCl) and 4 (natural brine) respectively. In these figures the LMO porous electrode on the left hand side and the PPy porous electrode on the right are separated by the $0.1 \mathrm{~cm}$ thick porous separator where only lithium and chloride ion transport occurs.

During operation of the reactor at $20 \mathrm{~mA}$ charging current in dilute $\mathrm{LiCl}$ electrolyte, lithium ions pass from the solid LMO into the liquid electrolyte and move toward the PPy electrode while chloride ions move in the opposite direction to keep electroneutrality. At the PPy porous electrode chloride ions desorb and move toward the LMO

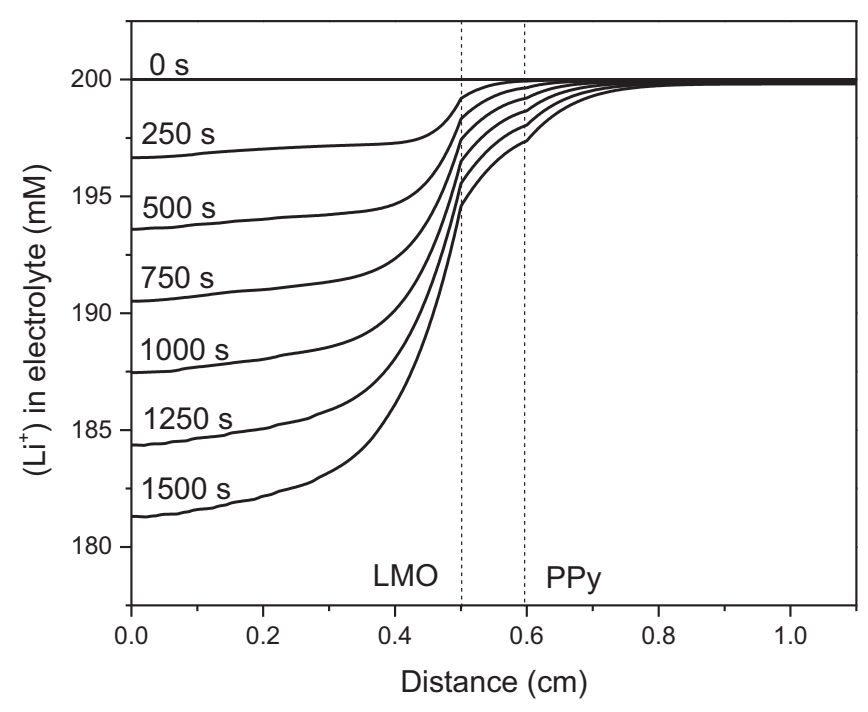

Figure 6. Concentration profiles of $\left[\mathrm{Li}^{+}\right]$in brine along the distance in the $1 \mathrm{D}$ reactor for data in Fig. 4, lithiation from natural brine at $20 \mathrm{~mA}$.

electrode while lithium ions move to the right to compensate charge. At the separator there is no source or sink of lithium or chloride ions which can only diffuse and migrate in the concentration and potential gradients respectively. The lithium chloride concentration increases with time during delithiation but the concentration distribution is not homogeneous due to the different diffusion coefficient of $\mathrm{Li}^{+}$and $\mathrm{Cl}^{-}$ in dilute $0.05 \mathrm{M} \mathrm{LiCl}^{38}$

In the lithium chloride capture by lithium deficient LMO (discharge step) the $\mathrm{Li}^{+}$concentration profiles shown in Figure 6 are quite different from those for the reactor charging step since in brine electrolyte several cations can compensate charge during the chloride uptake by the PPy porous electrode. As a result lithium migration is not necessary to guarantee local electroneutrality and most of the lithium extraction takes place within the LMO porous electrode. The concentration profiles of $\mathrm{Cl}^{-}, \mathrm{Na}^{+}, \mathrm{K}^{+}, \mathrm{Mg}^{2+}$, and $\mathrm{B}_{2} \mathrm{O}_{7}{ }^{2-}$ can be seen in Figures 8-12 in the supporting information and it appears that the concentration of the non intercalating cations slightly increases when the $\mathrm{Li}^{+}$concentration decreases due to charge compensation.

For comparison of the present reactor a hybrid supercapacitor has been simulated, where the polypyrrole electrode has been replaced by an electrostatic double layer capacitor electrode that can adsorb and release lithium ions. For the same reactor working as a hybrid supercapacitor with $\mathrm{Li}^{+}$ions adsorbing at the negative electrode on the right hand side $\left(v_{\mathrm{Li}}=1, v_{\mathrm{Cl}}=0\right)$ the concentration distribution is very different from that in Figure 5 as can be seen in Figure 7. The distribution in this case is symmetric on both sides of the separator but the carbon capacitive electrode on the right hand side shows a decrease of $\mathrm{LiCl}$ concentration that compensates the increase on the left hand side positive electrode in agreement with the results of Hao et al. ${ }^{28}$ The important difference here is that in the extracting reactor the total $\mathrm{LiCl}$ concentration changes while in the hybrid supercapacitor it remains constant. The symmetry in the lithium ion concentration arises from the diffusion of lithium ion in the hybrid supercapacitor rather than chloride in the case of PPy capacitor.

The surface concentration of lithium ions at the surface of LMO particles as a function of the position in the porous electrode is shown in Figures $8 \mathrm{a}$ and $8 \mathrm{~b}$. Both during the extraction and recovery steps at $20 \mathrm{~mA}$ the surface concentration increases and decreases respectively with electrolysis time almost uniformly across the porous LMO electrode. However, for the lithium chloride release in $50 \mathrm{mM} \mathrm{LiCl}$ electrolyte a depletion of the surface $\mathrm{Li}^{+}$concentration on the surface of LMO particles is observed toward the porous separator, but the effect is not observed in natural brine where there is a large concentration of salts. 


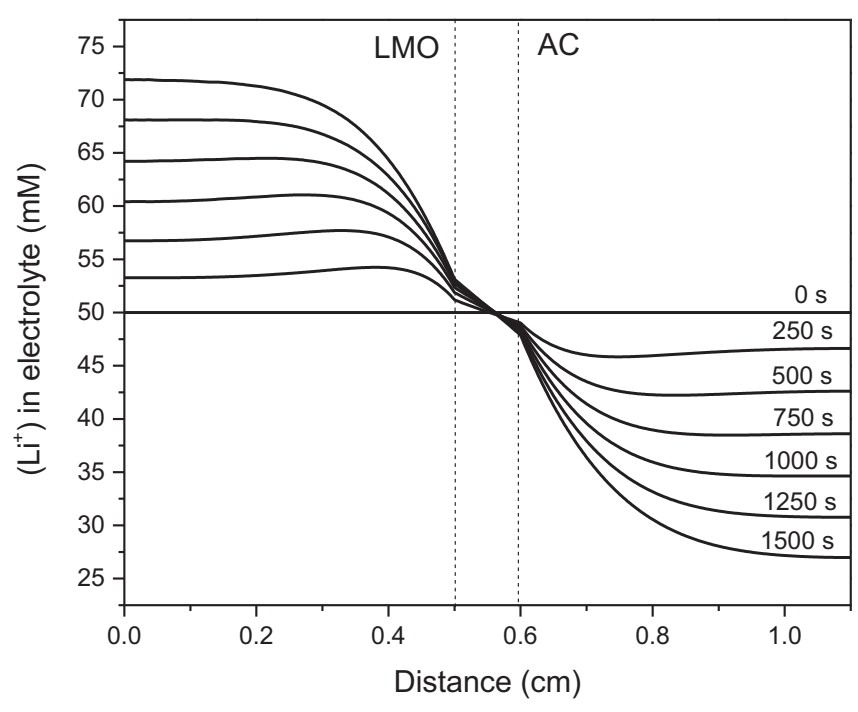

Figure 7. Concentration profiles of $\left[\mathrm{Li}^{+}\right]$in the electrolyte along the distance in the 1D hybrid supercapacitor for data in Fig. 3, $0.05 \mathrm{M} \mathrm{LiCl}$ and $20 \mathrm{~mA}$ but with $\mathrm{AC}$ porous electrode on the right hand side. $\left(\nu_{\mathrm{Li}}=1, \nu_{\mathrm{cl}}=0\right)$.

A limitation observed both experimentally (Figure 13 in SI) and in the simulations to achieve the theoretical $148 \mathrm{mAh} / \mathrm{g} \mathrm{LMO}$ is the overpotential at high applied currents. Figure 9 depicts charging curves for a 10:1 PPy to LMO mass ratio for different currents from $1 \mathrm{~mA}$ to $60 \mathrm{~mA}$.

The specific capacity per gram of LMO decreases from almost the theoretical value at $1 \mathrm{~mA}$ to less than half at $60 \mathrm{~mA}$ at the cutoff potential. This is due to the overpotentials for the insertion and release of $\mathrm{Li}^{+}$ions to and from $\mathrm{LiMn}_{2} \mathrm{O}_{4}$ electrode (interfacial kinetics and diffusion) and also due to the total ohmic drop in the electrolyte filling the 3D porous electrodes and the separator. As a result the cutoff potentials are reached at lower specific charge and less lithium chloride extraction is achieved.

The simulated curves for the electrolyte potential profiles in the reactor are shown in Figure 10. As the applied current increases, the ohmic drop represents a significant proportion of the reactor potential and at $60 \mathrm{~mA}$ it reaches $310 \mathrm{mV}$ therefore the reactor potential reaches the cutoff potential at shorter time in good agreement with the experimentally observed reactor resistance, of $3.6 \Omega$.

Therefore, a compromise between the applied current and the lithium extraction efficiency should be achieved by the reactor geometry design. A detailed study of the $\mathrm{LiCl}$ extraction efficiency and the effect of mass transport with electrolyte circulation through the reactor will be reported in a future communication.

\section{Conclusions}

A numerical model for the operation of a novel electrochemical reactor to extract lithium from natural brine and recovery in a dilute $\mathrm{LiCl}$ electrolyte has been developed. The selective extraction of $\mathrm{Li}^{+}$ was achieved using lithium deficient $\mathrm{Li}_{1-\mathrm{x}} \mathrm{Mn}_{2} \mathrm{O}_{4}$ loaded on a porous conducting coke packed bed electrode and $\mathrm{Cl}^{-}$anions were simultaneously adsorbed by polypyrrole upon oxidation. The experimental study of the reactor performance and the comparison with the simulation during lithium extraction from brine and recovery in dilute $\mathrm{LiCl}$ has been validated for the first time to the best knowledge of the authors.

While the simulation could reproduce the previous model for an asymmetric supercapacitor consisting of LMO and activated carbon electrode, an important difference has been shown with the reactor for the selective extraction of $\mathrm{LiCl}$ : In the former case the total lithium concentration remains constant in the reactor while in the latter case

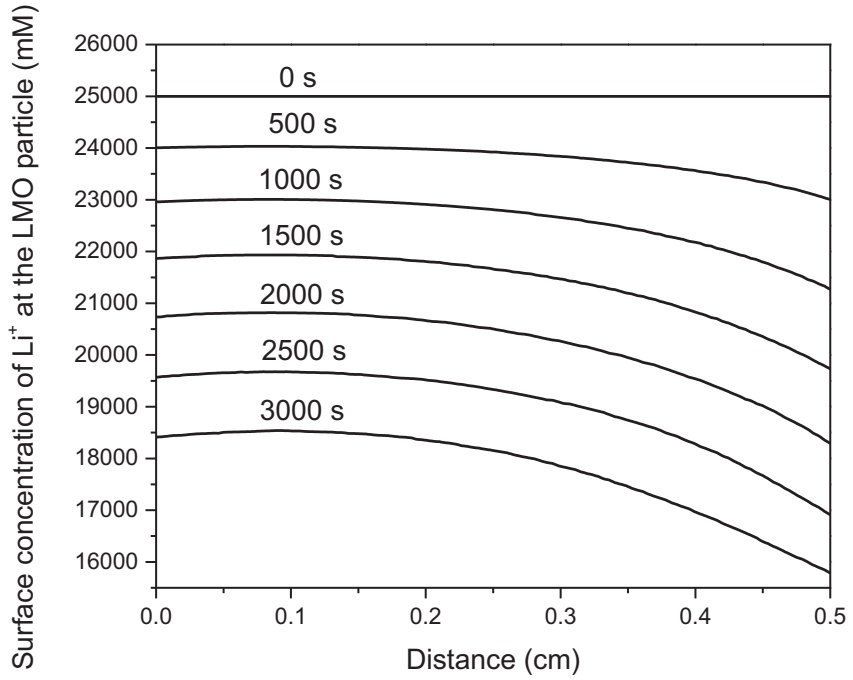

(a)

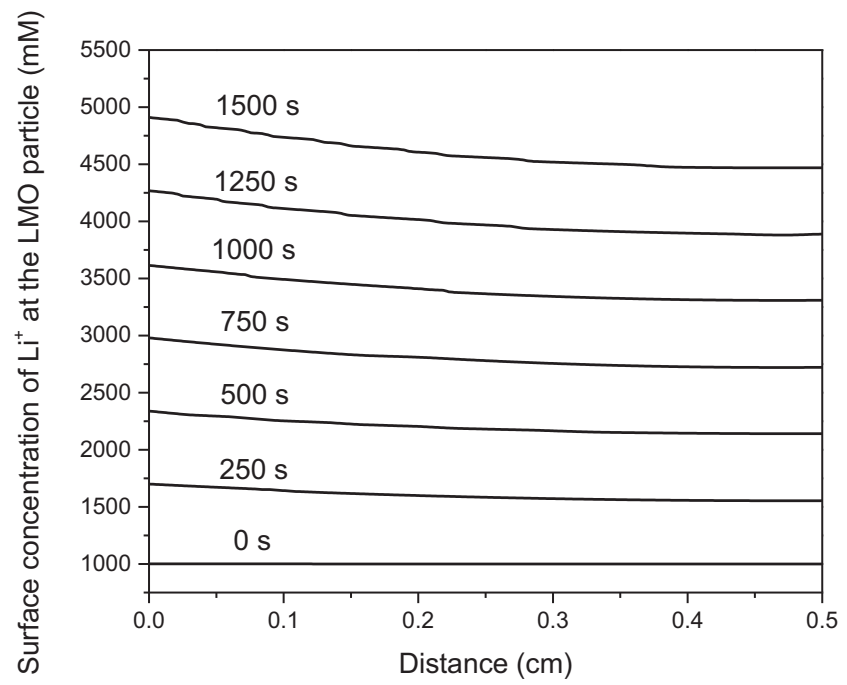

(b)

Figure 8. a: Surface concentration of $\mathrm{Li}^{+}$at the $\mathrm{LMO}$ particle in the left packed bed electrode. Numbers indicate the time during the lithium release (delithiation) process in $50 \mathrm{mM} \mathrm{LiCl}$. b: Surface concentration of $\mathrm{Li}^{+}$at the LMO particle in the left packed bed electrode. Numbers indicate the time during the lithium capture (intercalation into LMO) process from natural brine.

$\mathrm{LiCl}$ concentration in the electrolyte decreases during extraction and increases during release at the recovery step.

The model was used to investigate the concentration distribution of lithium, chloride and non-intercalation ions along the reactor, as well as the solid-electrolyte potential difference gradients and the electrolyte potential gradients in the porous electrochemically active electrodes and in the separator.

Among the limitations in the scale up of the electrochemical reactor are the LMO to PPy mass ratio, the ohmic drop in the electrolyte as the current density is increased and the $4 \%$ extraction capacity of LMO. Careful design of the reactor and operating conditions should be optimized.

\section{Acknowledgments}

VF, MT and EJC are Research Fellows of CONICET. VCER acknowledges a joint CONICET-YTEC doctoral fellowship. Funding from Agencia Nacional de Promoción Cientílfica y Tecnológica 


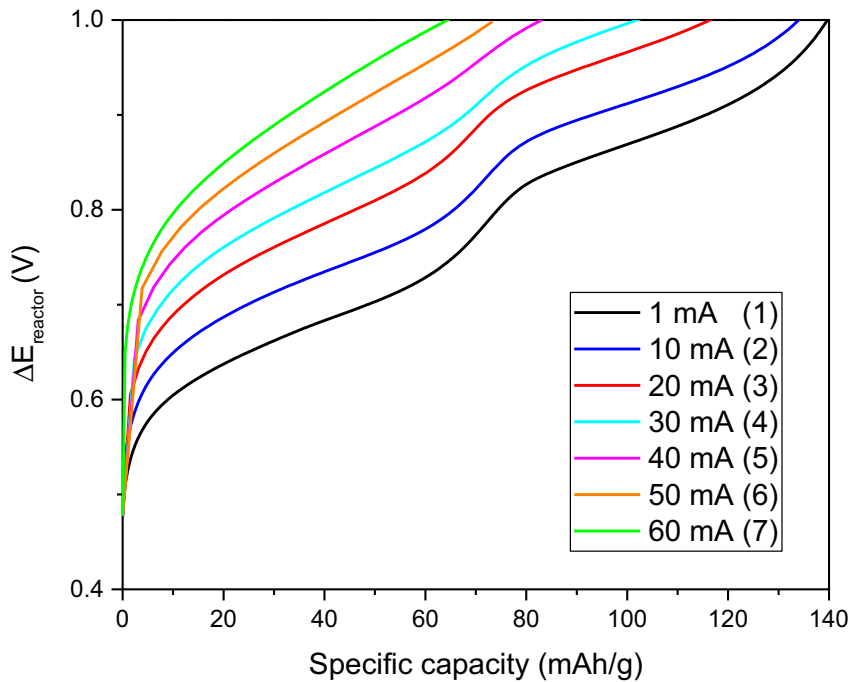

Figure 9. Effect of delithiation current on the potential charge curve within the potential cutoff limits.

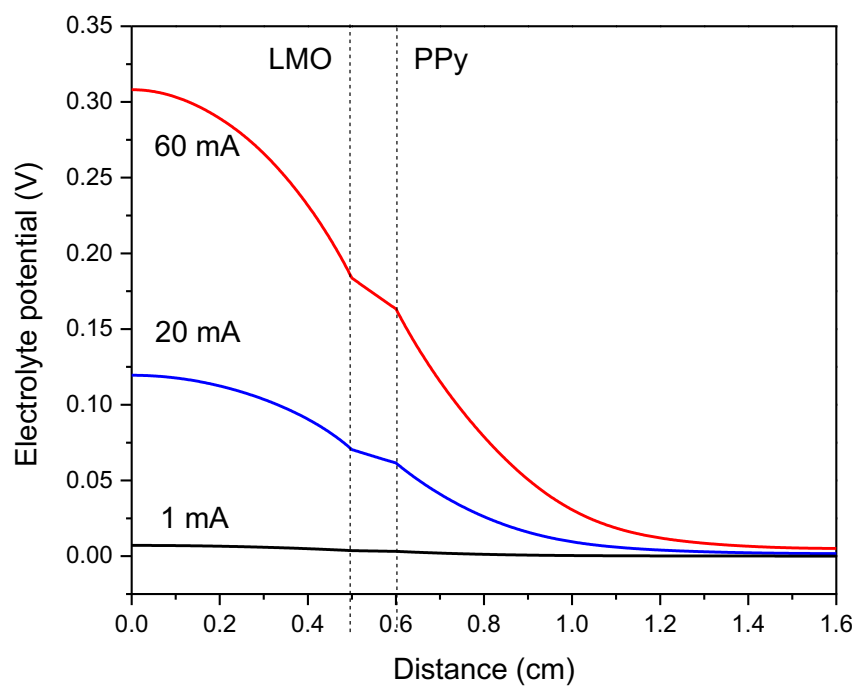

Figure 10. Simulated curves of the electrolyte potential profile in the reactor at different applied currents during $\mathrm{LiCl}$ recovery in $50 \mathrm{mM} \mathrm{LiCl}$ electrolyte.

(ANPCyT), through PICT V-2014 3654 and FITR-INDUSTRIA 9/2013 are gratefully acknowledged.

\section{ORCID}

M. Tagliazucchi (10 https://orcid.org/0000-0003-4755-955X

V. Flexer (iD https://orcid.org/0000-0002-4385-8846

E. J. Calvo (1) https://orcid.org/0000-0003-0397-2406

\section{References}

1. For instance a Tesla S electric car with 7104 cells $\times 2,4 \mathrm{Ah} /$ cell $=17.050 \mathrm{Ah}$. Each 2.4 Ah NCA cell has $0.91 \mathrm{~g}$ of $\mathrm{Li}$ and the car battery $6,5 \mathrm{~kg}$ of Li. Compare to an i-phone with $1400 \mathrm{mAh} \mathrm{LNC}$ battery with $0.527 \mathrm{~g} \mathrm{Li}$, in (Note).

2. V. Flexer, C. F. Baspineiro, and C. I. Galli, Science of The Total Environment, 639, 1188 (2018).

3. S. Border and L. Sawyer, Transactions of the Institutions of Mining and Metallurgy, Section B: Applied Earth Science, 123, 95 (2014).

4. B. Swain, Separation and Purification Technology, 172, 388 (2017).
5. Accenture, Lithium Producers Report, in, Bright Minds Challenge Prize Communication, ed., E. J. Calvo Editor (2017).

6. H. Kanoh, K. Ooi, Y. Miyai, and S. Katoh, Langmuir, 7, 1841 (1991).

7. H. Kanoh, K. Ooi, Y. Miyai, and S. Katoh, Separation Science and Technology, 28, 643 (1993).

8. H. Kanoh, Q. Feng, T. Hirotsu, and K. Ooi, Journal of the Electrochemical Society, 143, 2610 (1996).

9. M. Pasta, A. Battistel, and F. La Mantia, Energy and Environmental Science, 5, 9487 (2012).

10. R. Trocoli, A. Battistel, and F. La Mantia, ChemSusChem, 8, 2514 (2015).

11. R. Trocoli, A. Battistel, and F. L. Mantia, Chemistry - A European Journal, 20, 9888 (2014).

12. J. Lee, S. H. Yu, C. Kim, Y. E. Sung, and J. Yoon, Physical Chemistry Chemical Physics, 15, 7690 (2013).

13. S. Kim, J. Lee, J. S. Kang, K. Jo, S. Kim, Y. E. Sung, and J. Yoon, Chemosphere, 125, 50 (2015).

14. J.-S. Kim, Y.-H. Lee, S. Choi, J. Shin, H.-C. Dinh, and J. W. Choi, Environmental Science \& Technology, 49, 9415 (2015).

15. T. Hoshino, Fusion Engineering and Design, 88, 2956 (2013).

16. T. Hoshino, ECS Transactions, 58, 173 (2013).

17. N. Intaranont, N. Garcia-Araez, A. L. Hector, J. A. Milton, and J. R. Owen, Journal of Materials Chemistry A, 2, 6374 (2014).

18. X. Liu, X. Chen, Z. Zhao, and X. Liang, Hydrometallurgy, 146, 24 (2014).

19. M.-Y. Zhao, Z.-Y. Ji, Y.-G. Zhang, Z.-Y. Guo, Y.-Y. Zhao, J. Liu, and J.-S. Yuan, Electrochimica Acta, 252, 350 (2017).

20. K. Okano, Y. Takami, S. Yanase, and T. Oi, Energy Procedia, 71, 140 (2015).

21. E. Guyot, S. S. Seghir, S. Diliberto, J.-M. Lecuire, and C. Boulanger, Electrochemistry Communications, 29 (2012).

22. C. Jiang, Y. Wang, Q. Wang, H. Feng, and T. Xu, Industrial and Engineering Chemistry Research, 53, 6103 (2014).

23. T. Ryu, D. H. Lee, J. C. Ryu, J. Shin, K. S. Chung, and Y. H. Kim, Hydrometallurgy, 151, 78 (2015).

24. T. Ryu, J. C. Ryu, J. Shin, D. H. Lee, Y. H. Kim, and K. S. Chung, Industrial and Engineering Chemistry Research, 52, 13738 (2013).

25. A. Somrani, A. H. Hamzaoui, and M. Pontie, Desalination, 317, 184 (2013).

26. F. Marchini, D. Rubi, M. del Pozo, F. J. Williams, and E. J. Calvo, Journal of Physical Chemistry C, 120(29), 15875 (2016).

27. L. L. Missoni, F. Marchini, M. D. Pozo, and E. J. Calvo, Journal of the Electrochemical Society, 163, A1898 (2016).

28. C. Hao, X. Wang, Y. Yin, and Z. You, Journal of Electronic Materials, 45(1), 515 (2015).

29. Y.-G. Wang and Y.-Y. Xia, Journal of The Electrochemical Society, 153, A450 (2006).

30. F. Marchini, E. J. Calvo, and F. J. Williams, Electrochimica Acta, 269, 706 (2018).

31. F. Marchini, F. J. Williams, and E. J. Calvo, Journal of Electroanalytical Chemistry, 819, 428 (2018).

32. R. DSM, Bright Minds Challenge award for Ernesto Julio Calvo with Inquimae, in, https://www.dsm.com/corporate/media/informationcenter-news/2017/06/2017-0613-dsm-and-partners-announce-bright-minds-challenge-award-winner.html.

33. M. Doyle, J. Newman, A. S. Gozdz, C. N. Schmutz, and J. M. Tarascon, Journal of the Electrochemical Society, 143, 1890 (1996).

34. T. F. Fuller, M. Doyle, and J. Newman, Journal of the Electrochemical Society, 141, 1 (1994).

35. J. Newman and K. E. Thomas-Alyea, Electrochemical Systems, John Wiley \& Sons, Inc., Hoboken, New Jersey (2004).

36. Yong-gang Wang and Yong-yao Xia*, Journal of The Electrochemical Society, 153, A450 (2006).

37. F. X. Wang, S. Y. Xiao, Y. S. Zhu, Z. Chang, C. L. Hua, Y. P. Wua, and R. Holze, Journal of Power Sources, 246, 19 (2014).

38. K. Tanaka and M. Nomura, Journal of the Chemical Society, Faraday Transactions 1: Physical Chemistry in Condensed Phases, 83, 1779 (1987).

39. A. M. Johnson and J. Newman, Journal of the Electrochemical Society, 118, 510 (1971).

40. J.-H. Kim, Y.-S. Lee, A. K. Sharma, and C. G. Liu, Electrochimica Acta, 52, 1727 (2006).

41. F. X. Wang, S. Y. Xiao, Y. S. Zhu, Z. Chang, C. L. Hu, Y. P. Wu, and R. Holze, Journal of Power Sources, 246, 19 (2014).

42. COMSOL, Batteries \& Fuel Cells Module. User's Guide, in, COMSOL (2016).

43. P. Turq, F. Lantelme, and M. Chemla, Electrochimica Acta, 14, 1081 (1969).

44. L. Yuan-Hui and S. Gregory, Geochimica et Cosmochimica Acta, 38, 703 (1974).

45. M. Griffiths, C. P. de León, and F. C. Walsh, AIChE Journal, 51, 682 (2005).

46. F. F. Rivera, C. P. d. León, F. C. Walsh, and J. L. Nava, Electrochimica Acta, 161, 436 (2015).

47. P. Trinidad and F. C. Walsh, Electrochimica Acta, 41, 493 (1996).

48. D. Guyomard and J. M. Tarascon, Journal of the Electrochemical Society, 139, 937 (1992).

49. D. Guyomard and J. M. Tarascon, Journal of the Electrochemical Society, 140, 3071 (1993).

50. D. Guyomard and J. M. Tarascon, Advanced Materials, 6, 408 (1994). 